\title{
The impact of Pegylated liposomal doxorubicin in recurrent ovarian cancer: an updated meta-analysis of randomized clinical trials
}

\author{
Xin-Ru Li ${ }^{1}$, Yi Zhu² (D), Guo-Nan Zhang ${ }^{3,4^{*}}$ (D), Jian-Ming Huang ${ }^{5}$ (D) and Li-Xia Pei ${ }^{1,4}$ (D)
}

\begin{abstract}
Background: Previous meta-analysis studies suggested that pegylated liposomal doxorubicin (PLD) may improve the survival rate of patients with recurrent ovarian cancer. The aim of the present meta-analysis, then, was to further update the role of PLD in the treatment of recurrent ovarian cancer.

Methods: We performed a literature search using the electronic databases Medicine, EMBASE, Web of Science, and the Cochrane Library to 27 July 2020. We only restricted the randomized clinical trials. Study-specific hazard ratios and $95 \%$ confidence interval $(\mathrm{HR} / 95 \% \mathrm{Cl})$ and risk ratios and 95\% confidence interval (RR/95\% Cl) were pooled using a random-effects model.

Results: Ten studies (12 trials) were included after screening 940 articles. We categorized the eligible studies into two groups: the doublet regimens (four trials, 1767 patients) showed that PLD plus carbo provided superior progression-free survival (PFS) (HR, 0.85; 95\% Cl, 0.74-0.97) and similar overall survival (OS) (HR, 1.00; 95\% Cl, 0.881.14) compared to paclitaxel (PAC) plus carboplatin (carbo). PLD plus carbo was associated with significantly more anemia and thrombocytopenia, and other side effects were well tolerated. The monotherapy regimens (eight trials, 1980 patients) showed that PLD possessed a similar PFS (HR, 1.02; 95\% Cl, 0.90-1.16) and OS (HR, 0.88; 95\% Cl, 0.771.01) relative to other monotherapies. PLD alone was also more associated with mucositis/stomatitis and hand-foot syndrome, while other side effects were well tolerated.
\end{abstract}

Conclusions: In platinum-sensitive recurrent ovarian cancer, PLD plus carbo was more effective than PAC plus carbo, while in platinum-resistant or -refractory recurrent ovarian cancer, PLD exhibited similar survival to other monotherapies. Regarding side effects, PLD plus carbo and mono chemotherapy were both well tolerated.

Keywords: Ovarian neoplasms, Pegylated liposomal doxorubicin, Progression-free survival, Overall survival, Meta-analysis

\footnotetext{
* Correspondence: zhanggn@hotmail.com

${ }^{3}$ Department of Gynecological Oncology, the Affiliated Cancer Hospital,

School of Medicine, University of Electronic Science and Technology of

China, Sichuan Cancer Hospital \& Institute, No.55 Ren-min-nan Road,

Chengdu 610041, Sichuan Province, People's Republic of China

${ }^{4}$ School of Clinical Medicine, Chengdu University of Traditional Chinese

Medicine, No.37 Shi-er-qiao Road, Chengdu 610072, Sichuan Province,

People's Republic of China

Full list of author information is available at the end of the article
}

(c) The Author(s). 2021 Open Access This article is licensed under a Creative Commons Attribution 4.0 International License, which permits use, sharing, adaptation, distribution and reproduction in any medium or format, as long as you give appropriate credit to the original author(s) and the source, provide a link to the Creative Commons licence, and indicate if changes were made. The images or other third party material in this article are included in the article's Creative Commons licence, unless indicated otherwise in a credit line to the material. If material is not included in the article's Creative Commons licence and your intended use is not permitted by statutory regulation or exceeds the permitted use, you will need to obtain permission directly from the copyright holder. To view a copy of this licence, visit http://creativecommons.org/licenses/by/4.0/ The Creative Commons Public Domain Dedication waiver (http://creativecommons.org/publicdomain/zero/1.0/) applies to the data made available in this article, unless otherwise stated in a credit line to the data. 


\section{Introduction}

Ovarian cancer is one of the most common gynecologic malignancies, with the third highest incidence of gynecologic tumors and the highest mortality rate. Because ovarian cancer is not easy to detect at the early stages, it is usually diagnosed at an advanced stage, and its 5-year relative survival rate is comparatively low. The lifetime risk for ovarian cancer is approximately 1 in 75 , and the likelihood of dying from this malignancy is 1 in 100 [1, 2]. Cytoreductive surgery followed by platinum-based chemotherapy remains the mainstay of treatment in ovarian cancer. Yet, despite complete remission through the very best treatments, approximately $70-80 \%$ of patients with International Federation of Gynecology and Obstetrics stage III to IV disease experience a relapse within 5 years $[3,4]$. Thus, ovarian cancer remains a serious threat to women's health worldwide.

For patients with platinum-sensitive recurrent ovarian cancer, we usually choose carboplatin (carbo) in combination with paclitaxel (PAC) as the first-line standard chemotherapy regimen, but this regimen exhibits more non-hematologic toxicity, which results in early discontinuation of treatment. Specifically, this regimen imposes high rates of alopecia, hypersensitivity, and neurotoxicity [5], and platinum re-challenge therapy in platinumrefractory or -resistant patients usually results in low response rates and short survival. In this particular setting, chemotherapy with single agents shows activity and lower toxicity than combination chemotherapy [6]. Single-agent second-line treatments include non-platinum compounds such as PAC, topotecan, PLD, gemcitabine, etoposide, vinorelbine, and bevacizumab, and we typically choose sequential single chemotherapeutic agents depending upon the various conditions exhibited by patients. While treatment options for recurrent ovarian cancer have increased, the majority of these patients will still eventually die from ovarian cancer. Therefore, the goal of therapy in the recurrent setting should not only focus on improving the length of life but also include a thoughtful review of anticipated side effects and overall quality of life.

PLD-anthracycline chemotherapy derived from doxorubicin-was the first FDA-approved cancer nanomedicine [7], and was used as early as 2014 for the treatment of ovarian and breast cancer, multiple myeloma, and Kaposi sarcoma [8]. The 2017 NCCN Guidelines recommended that carbo combined with PLD be added as one of the initial chemotherapy regimens for ovarian cancer. Carbo combined with PLD was thus recommended for patients with recurrent platinum-sensitive ovarian cancer, and PLD monotherapy was recommended for relapsed platinum-resistant ovarian cancer patients. The 2018 NCCN Guidelines included PLD as a first-line chemotherapy regimen for ovarian cancer, and a regimen of carbo combined with PLD is recommended for initial treatment of stage-1 ovarian cancer. The 2019 NCCN Guidelines recommend that PLD plus bevacizumab be used as a potential treatment option for patients with platinumresistant recurrent ovarian cancer. Clinical studies have shown that compared with other standard chemotherapy regimens, PLD possesses a non-inferior survival rate and is well tolerated, exhibiting reduced alopecia and neurotoxicity [9].

Previous studies $[10,11]$ showed that PLD is effective and well tolerated in the treatment of ovarian cancer. However, because these two meta-analyses were published earlier and contained fewer trials, we added the most recent trials and performed an updated meta-analysis. We trust that our study results will soon facilitate the selection of chemotherapy regimens for recurrent ovarian cancer patients.

\section{Methods}

\section{Search strategy}

We conducted this meta-analysis framework under the guidance of PRISMA, and performed queries of the literature using the electronic databases Medicine, EMBASE, Web of Science, and the Cochrane Library to 27 July 2020. The search MeSH terms and free words used were 1) "Pegylated Liposomal Doxorubicin," "Caelyx," "Lipodox," "Doxil," 2) "ovarian cancer," "ovarian neoplasm," "ovarian carcinoma, " and 3) "Randomized Controlled Trial." We did not limit the language for our searches or the studies included in the present investigation. The details of the search strategy are presented in Supplementary Material 1.

\section{Eligibility criteria}

The abstracts of all articles retrieved in the initial search were independently screened by two authors (X.R.L and L.X.P). The procedures were executed by the independent reviewers according to the following criteria. The inclusion criteria were 1) patients with histologically confirmed recurrent ovarian cancer; 2) patients with interventions involving PLD alone versus other monotherapy, or PLD plus carboplatin versus paclitaxel plus carboplatin; 3) outcome measures that involved survival outcome and adverse events; and 4) all RCT studies. The exclusion criteria were 1) patients not having previously received PLD; 2) patients not having undergone any examinations for ovarian cancer; 3 ) pediatric populations (<18 years of age); 4) animal/laboratory studies; 5) review articles, case reports, letters, commentaries, or conference proceedings; and 6) no histologic confirmation of recurrent ovarian cancer. Disagreements were discussed with a third author (Prof. G.N.Z) to achieve consensus.

For the present study, the same two authors who performed full-text screening independently conducted data extraction, and all inconsistencies were resolved by consensus. Selected full-text manuscripts were reviewed in detail to determine their relevance. The exclusion 
criteria were 1) those studies not within the current research aims; 2) studies with missing data; and 3) overlapping studies.

\section{Data extraction}

Data were extracted from the studies that we ultimately used, and data included first author, journal, year of publication, number, age and characteristics of patients, study design, and outcomes.

\section{Statistical analysis}

For survival variables such as progression-free survival (PFS) and overall survival (OS), we used hazard ratios (HR) and 95\% CI, which are presented as forest plots. For categorical variables, we used risk ratios (RR) and 95\% CI, which are also presented as forest plots. Heterogeneity across studies was evaluated using the $\mathrm{I}^{2}$ metric and Chi-squared test. We used the random-effects model to calculate the summary estimate if heterogeneity was shown $\left(\mathrm{I}^{2}>50 \%\right)$ across studies; otherwise, the fixedeffects model was used $\left(\mathrm{I}^{2} \leq 50 \%\right)$. If heterogeneity was uncovered across studies, we performed subgroup analyses based upon study design and then analyzed the subgroup results. If potential publication bias was shown across studies, we used Egger's linear regression test, as well as Begg's funnel plot. All statistical testing was conducted using the Review Manager 5.3 (Copenhagen, The Nordic Cochrane Centre, The Cochrane Collaboration, 2014) and Stata.15.0 (Stata-Corp, College Station, TX). All tests were two-sided with $P<0.05$ considered statistically significant, except for the heterogeneity test $(P<0.1)$ and publication bias $(P<0.1)$ in our meta-analyses.

\section{Results}

\section{Literature search}

We designated for initial evaluation a total of 940 articles using our electronic database search. After removing duplicate articles and screening the study titles and abstracts, 56 articles meeting the inclusion criteria underwent full-text assessment, resulting in 10 relevant studies [12-22]. A flowchart of the selection procedure is shown in Fig. 1.

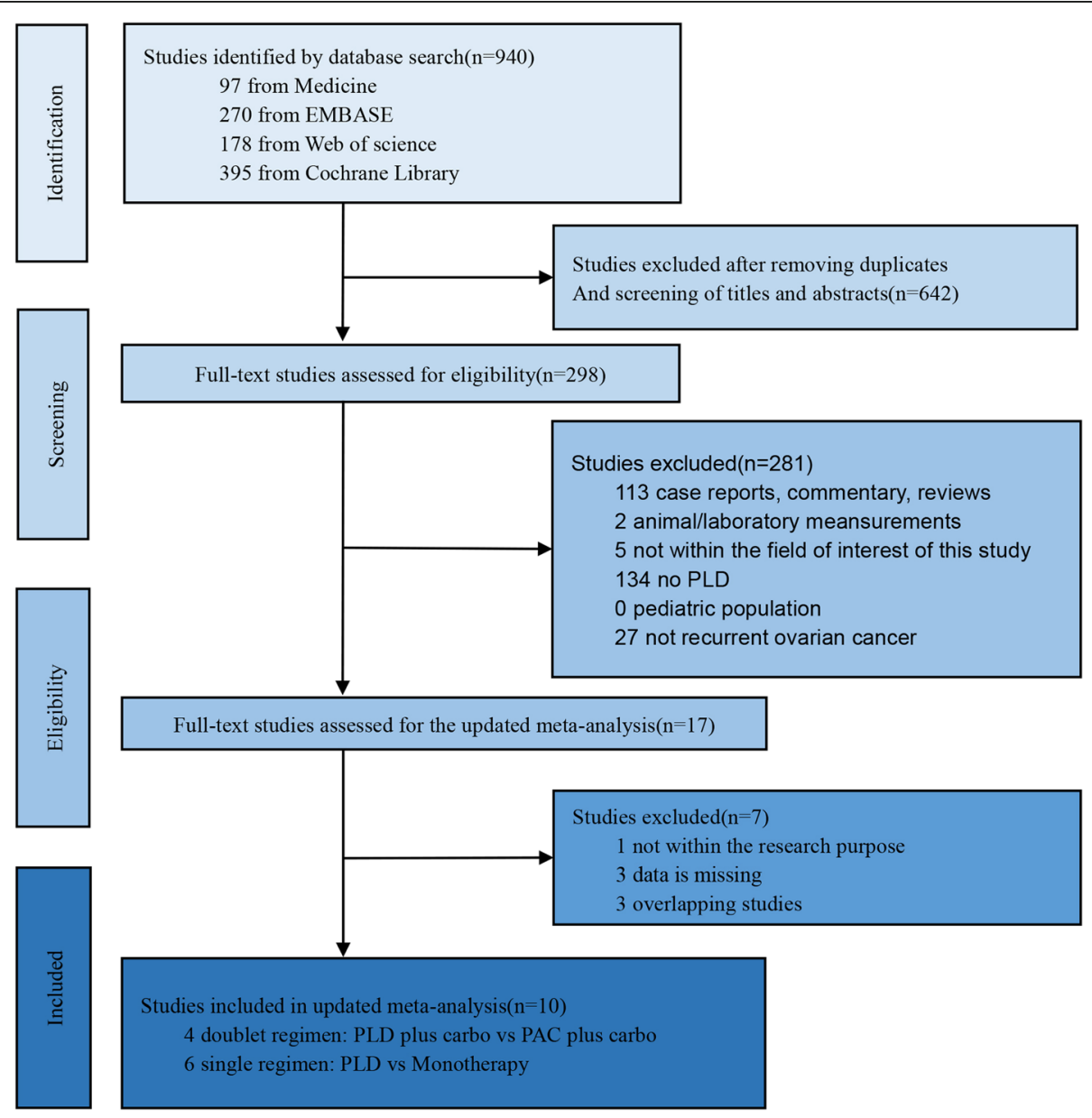

Fig. 1 Flow diagram showing selection of the studies for this updated meta-analysis 


\section{Study characteristics}

We categorized the 12 eligible trials into two groups: PLD plus carbo vs. PAC plus carbo (four trials [12-15]: 851 PLD plus carbo and 916 PAC plus carbo), and PLD vs. other monotherapies (eight trials [16-21]: 963 PLD and 1017 other monotherapies). Vergote 2009 [18] was utilized in both trials-PLD vs topotecan and PLD vs canfosfamide, and Kaye 2012 [21] was integrated into both trials-PLD vs. $200 \mathrm{mg}$ of olaparib and PLD vs. 400 $\mathrm{mg}$ of olaparib. All features of the included studies are depicted in Table.1. We assessed the study quality based on the Cochrane Collaboration tool and the criteria specified in Chapter 8 of the Cochrane Handbook for Systematic Reviews of Interventions [23] (Table 2). Each study was evaluated for potential bias and quality by two independent and experienced authors, and disagreements were resolved by consensus.

\section{Extraction of data}

Overall analysis of doublet regimens: PLD plus carbo vs. PAC plus carbo

PLD plus carbo was associated with a significant improvement in PFS (HR, 0.85; 95\% CI, 0.74-0.97; $\mathrm{I}^{2}=$ $28 \% ; p=0.02$ ), while OS was similar to the standard chemotherapy regimen PAC plus carbo (HR, 1.00; 95\% CI, 0.88-1.14; $\mathrm{I}^{2}=0 \% ; p=0.99$ ) (Fig. 2).

With respect to grade 3-4 toxicities, PLD plus carbo was associated with a decreased risk of an allergic reaction (RR, 0.38; 95\% CI, 0.19-0.78; $\mathrm{I}^{2}=0 \% ; p<0.01$ ), arthralgia/myalgia (RR, 0.19; 95\% CI, 0.05-0.68; $\mathrm{I}^{2}=0 \%$; $p=0.01$ ), and neutropenia ( $\mathrm{RR}, 0.76$; 95\% CI, 0.67-0.86; $\left.\mathrm{I}^{2}=0 \% ; p<0.01\right)$. PLD plus carbo was also associated with an increased risk of anemia (RR, 1.82; 95\% CI, $1.22-2.71 ; \mathrm{I}^{2}=0 \% ; p<0.01$ ) and thrombocytopenia (RR, 2.67; 95\% CI,1.94-3.67; $\mathrm{I}^{2}=0 \% ; p<0.01$ ). There was no difference in the risk of fatigue/asthenia (RR, 1.10; $95 \%$ CI, $\left.0.78-1.56 ; \mathrm{I}^{2}=0 \% ; p=0.57\right)$, mucositis/stomatitis (RR, 2.04; 95\% CI, 0.90-4.66; $\mathrm{I}^{2}=0 \% ; p=0.09$ ), handfoot syndrome (RR, 2.76; 95\% CI, 0.50-15.16; $\mathrm{I}^{2}=0 \%$; $p=0.24)$, or vomiting (RR, $1.38 ; 95 \% \mathrm{CI}, 0.72-2.66 ; \mathrm{I}^{2}=$ $44 \% ; p=0.33$ ) (Fig. 3).

\section{Overall analysis of monotherapy regimens: PLD vs. single agent}

PLD was similar in PFS (HR,1.02; 95\% CI, 0.90-1.16; $\left.\mathrm{I}^{2}=0 \% ; p=0.72\right)$ and $\mathrm{OS}(\mathrm{HR}, 0.88 ; 95 \% \mathrm{CI}, 0.77-1.01$; $\mathrm{I}^{2}=0 \% ; p=0.07$ ) to other single agents (Fig. 4).

With respect to grade 3-4 toxicities, PLD was associated with a significantly increased risk of mucositis/stomatitis (RR, 0.10; 95\% CI, 0.04-0.23; $\mathrm{I}^{2}=0 \% ; p<0.01$ ) and hand-foot syndrome (RR, 0.03; 95\% CI, 0.01-0.09; $\left.\mathrm{I}^{2}=0 \% ; p<0.01\right)$ compared with the other monotherapies. There were no differences in the risks of anemia (RR, 1.26; 95\% CI, 0.86-1.83; $\mathrm{I}^{2}=0 \% ; p=0.23$ ), vomiting
(RR, 0.97; 95\% CI, 0.57-1.66; $\mathrm{I}^{2}=38 \% ; p=0.91$ ), fatigue/ asthenia (RR, 1.09; 95\% CI, 0.73-1.64; $\mathrm{I}^{2}=19 \% ; p=$ 0.66), thrombocytopenia (RR, 1.73; 95\% CI, 0.93-3.24; $\left.\mathrm{I}^{2}=4 \% ; p=0.08\right)$, or neutropenia (RR, $1.32 ; 95 \% \mathrm{CI}$, 0.59-2.96; $\mathrm{I}^{2}=86 \% ; p=0.50$ ) (Fig. 5).

\section{Subgroup analysis}

We performed side-effect subgroup analysis with respect to neutropenia based upon the different drugs in the monotherapy regimens $\left(\mathrm{I}^{2}=86 \%\right)$ : one subgroup $[18,19]$ showed that canfosfamide and patupilone correlated with lower risk than PLD (RR, 0.39; 95\% CI, 0.21-0.72; $\left.\mathrm{I}^{2}=33 \% ; p<0.01\right)$, while the other subgroup $[16-18,20]$ showed that gemcitabine, topotecan, Lifastuzumab vedotin (LIFA), and olaparib reflected higher risk than PLD (RR, 2.26; 95\% CI, 1.61-3.17; $\mathrm{I}^{2}=0 \% ; p<0.01$ ). We then performed subgroup analysis for the differences in toxicity and side effects based on the different doses of PLD. In doublet regimens, we observed anemia at $30 \mathrm{mg} /$ $\mathrm{m}^{2}$ vs. $45 \mathrm{mg} / \mathrm{m}^{2}$ PLD ( $\left.\mathrm{I}^{2}=0 \%\right)$, and thrombocytopenia at $30 \mathrm{mg} / \mathrm{m}^{2}$ vs. $45 \mathrm{mg} / \mathrm{m}^{2}$ PLD $\left(\mathrm{I}^{2}=0 \%\right)$. There was, however, no difference in the incidence of adverse reactions at the different doses of PLD. For monotherapy regimens, the incidence of mucositis/stomatitis was similar between $40 \mathrm{mg} / \mathrm{m}^{2}$ and $50 \mathrm{mg} / \mathrm{m}^{2}$ PLD $\left(\mathrm{I}^{2}=60.5 \%\right)$, and hand-foot syndrome was similar between $40 \mathrm{mg} / \mathrm{m}^{2}$ and $50 \mathrm{mg} / \mathrm{m}^{2}$ $\operatorname{PLD}\left(\mathrm{I}^{2}=30.2 \%\right)$.

\section{Publication bias}

To assess all studies with regard to PFS in potential publication bias, we used Egger's linear regression test ( $p=$ $0.635)$, as well as Begg's funnel plot $(p=0.592)$. The test results showed that this updated meta-analysis showed no significant publication bias (Supplementary Material 2).

\section{Discussion}

To the best of our knowledge, the present study is the most recently updated meta-analysis with respect to the curative effects and side effects of PLD in recurrent ovarian cancer chemotherapy. Our results suggest that PLD is as effective or better in the treatment of recurrent ovarian cancer compared to other therapies. The secondary indicators showed that most patients tolerated the therapy well and manifested no serious adverse reactions.

\section{Doublet regimens}

Our study results illustrated the superiority of platinum doublets of carbo plus PAC, carbo plus gemcitabine, and carbo plus PLD to single-agent platinum, and that carbo plus PLD was as effective as carbo plus PAC in women with highly sensitive and relapsed ovarian cancer [4, 22, $24,25]$. We therefore only selected and compared doublet regimens based on platinum in platinum-sensitive 


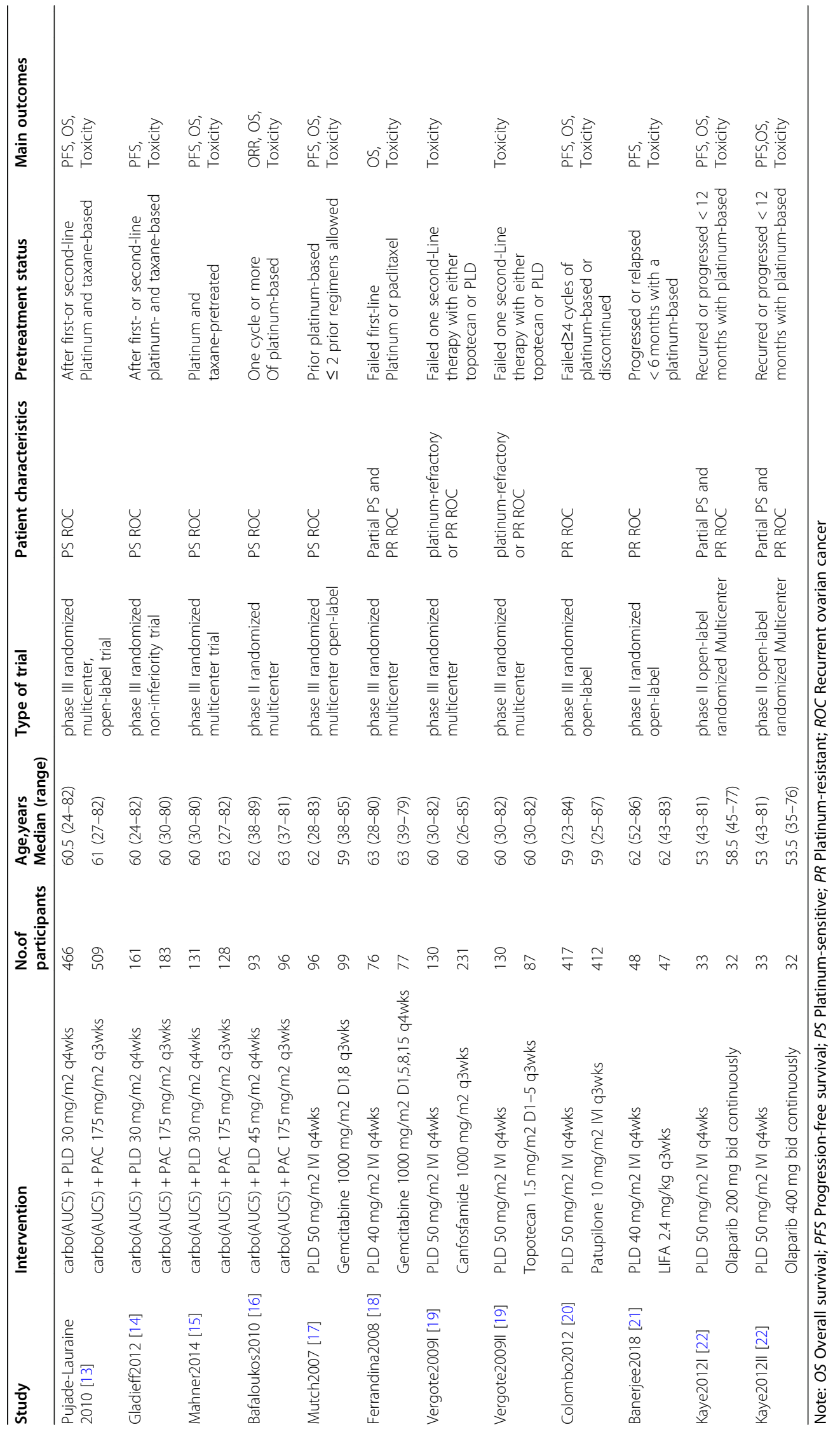


Table 2 Risk of bias for included studies

\begin{tabular}{|c|c|c|c|c|c|c|c|}
\hline Study & $\begin{array}{l}\text { Random sequence } \\
\text { generation }\end{array}$ & $\begin{array}{l}\text { Allocation } \\
\text { concealment }\end{array}$ & $\begin{array}{l}\text { Blinding of } \\
\text { participants } \\
\text { and personnel }\end{array}$ & $\begin{array}{l}\text { Blinding of } \\
\text { outcome } \\
\text { assessment }\end{array}$ & $\begin{array}{l}\text { Incomplete } \\
\text { outcome data }\end{array}$ & $\begin{array}{l}\text { Selective } \\
\text { reporting }\end{array}$ & other bias \\
\hline Pujade-Lauraine2010 [13] & Low risk & Low risk & High risk & Low risk & Low risk & Low risk & Low risk \\
\hline Gladieff2012 [14] & Low risk & Unclear risk & High risk & Low risk & Low risk & Low risk & Low risk \\
\hline Mahner2014 [15] & Low risk & Low risk & High risk & Low risk & Low risk & Low risk & Low risk \\
\hline Bafaloukos2010 [16] & Low risk & Low risk & Unclear risk & Low risk & Low risk & Low risk & Low risk \\
\hline Mutch2007 [17] & Low risk & Low risk & High risk & Unclear risk & Unclear risk & High risk & Low risk \\
\hline Ferrandina2008 [18] & Low risk & Low risk & High risk & Low risk & Low risk & Low risk & Low risk \\
\hline Vergote2009 [19] & Low risk & Low risk & High risk & Low risk & Low risk & Low risk & Low risk \\
\hline Colombo2012 [20] & Low risk & Low risk & High risk & Low risk & Low risk & Low risk & Low risk \\
\hline Banerjee2018 [21] & Low risk & Low risk & High risk & Low risk & Low risk & Low risk & Low risk \\
\hline Kaye2012 [22] & Low risk & Low risk & High risk & Low risk & Low risk & Low risk & Low risk \\
\hline
\end{tabular}

recurrent ovarian cancer. PLD plus carbo was superior in PFS without a change in OS. We found that of four doublet regimen trials, only the studies by PujadeLauraine2010 and Gladieff (2012) showed that PFS was prolonged in the PLD-plus-carbo group. In the PujadeLauraine study, $90 \%$ of the women received postprogression treatment, and the proportion of women in the PAC-plus-carbo arm who received PLD as poststudy therapy $(68 \%)$ was significantly higher than the proportion of women in the PLD-plus-carbo arm who received PAC $(43 \%, P<0.01)$, and this may have influenced the OS HR in the direction of the PAC-plus-carbo arm [11]. However, in the Gladieff study, OS was not assessed due to the fact that overall survival data were immature, such that there was no exact comparison between PFS and OS. Another perspective suggests the possibility that tumor cells that survive treatment with PLD plus carbo may be more aggressive or may be resistant to subsequent therapies. When the disease then recurs, it may progress more quickly or may be resistant to other therapies, thus negating any benefits on OS [10]. We also speculate that the study by Bafaloukos in 2010 (a phase-II study) did not have sufficient statistical power to assess OS, which may have affected the final results. The specific reasons for these disparate results remain unclear, and further research is therefore needed.

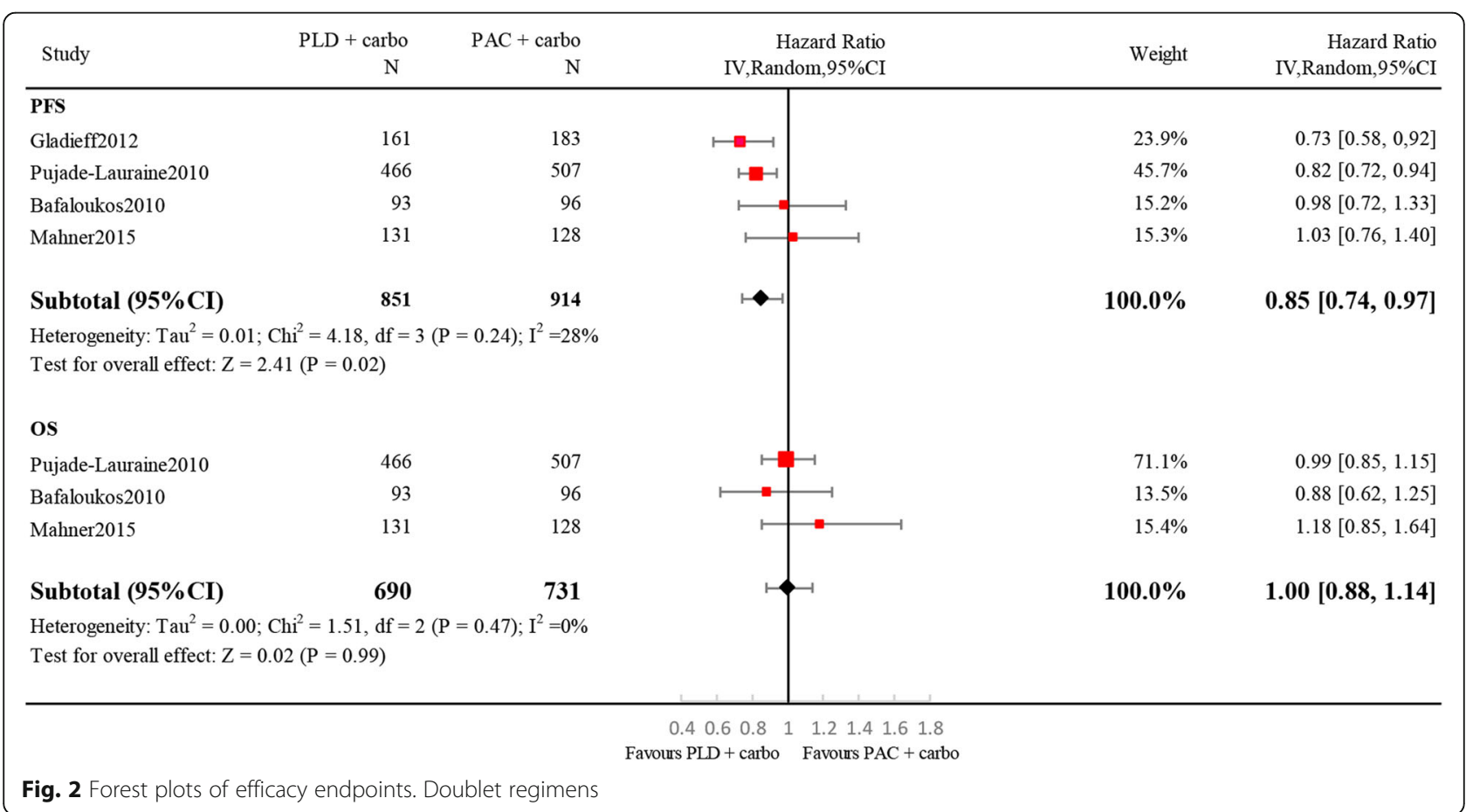




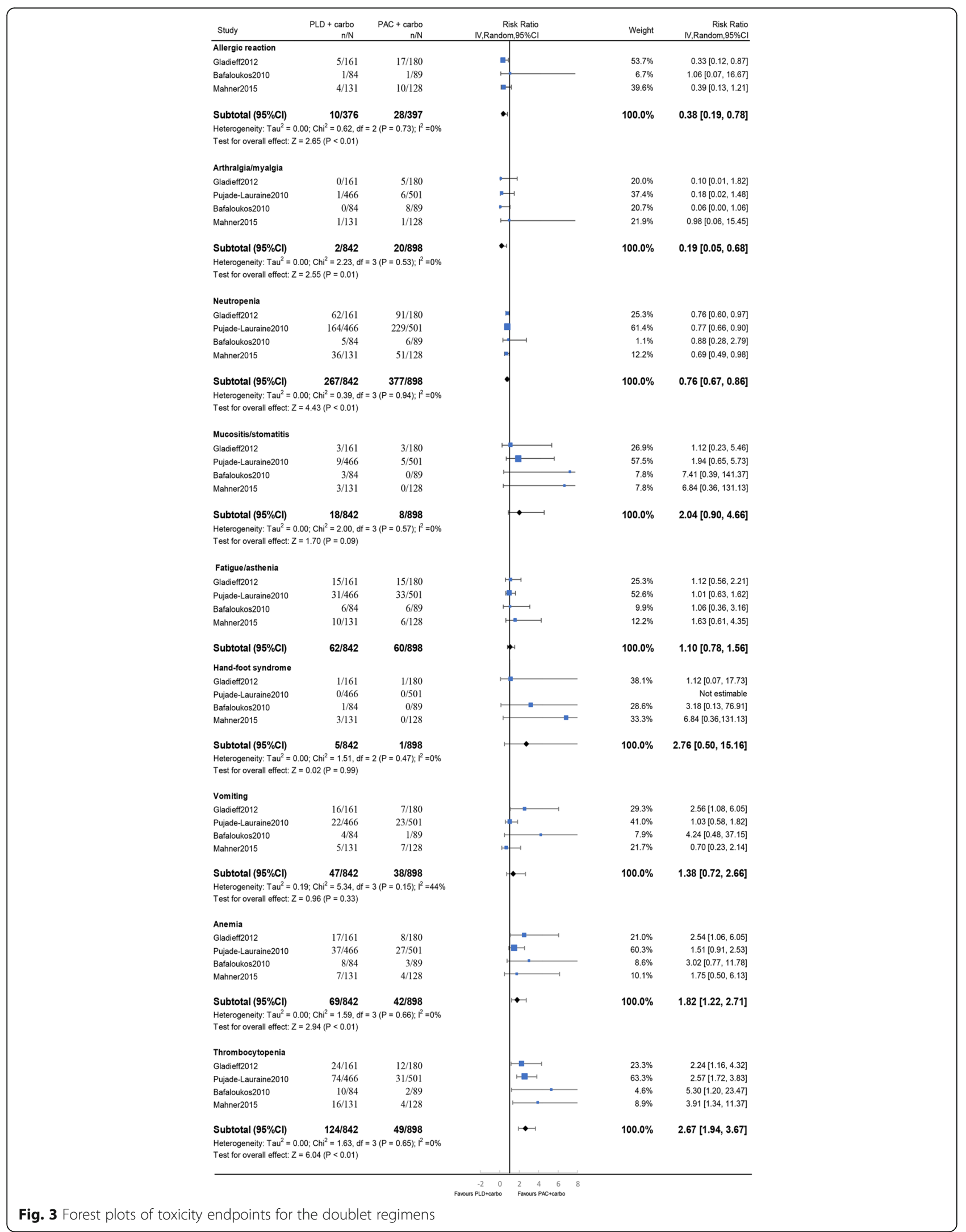




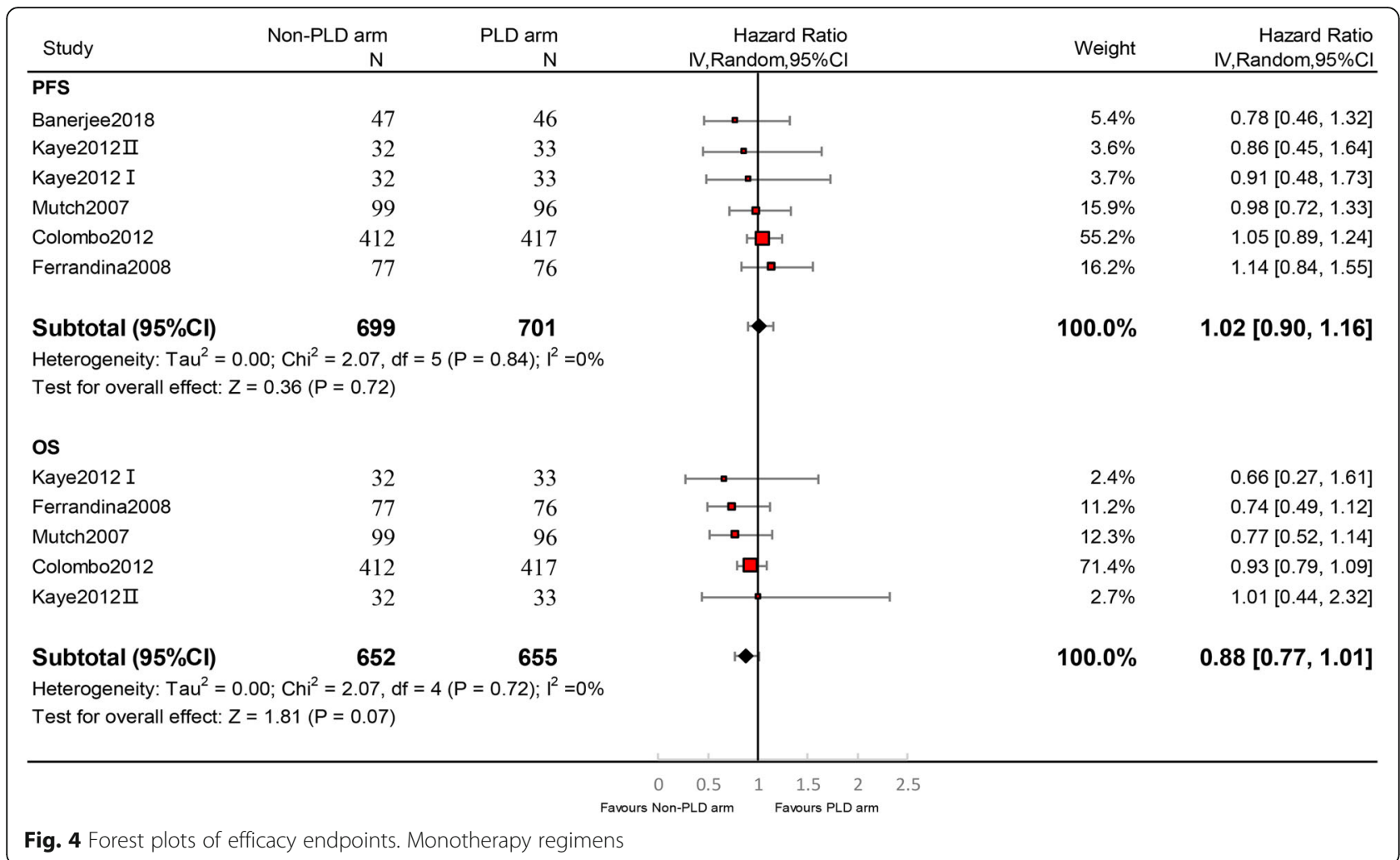

We compared PFS and OS based on different PLD doses, and did not observe any statistical significance between PLD at $30 \mathrm{mg} / \mathrm{m}^{2}$ every 4 weeks compared with $\mathrm{PLD}$ at $45 \mathrm{mg} / \mathrm{m}^{2}$ every 4 weeks. Therefore, we recommend that PLD at $30 \mathrm{mg} / \mathrm{m}^{2}$ every 4 weeks be used as the initial dosage in PLD-plus-carbo doublet regimens.

When we evaluated grade 2 or higher toxicities, we noted that PLD plus carbo was associated with a decreased risk of alopecia (RR, 0.09; 95\% CI, 0.07-0.12; $\left.\mathrm{I}^{2}=0 \% ; p<0.01\right)$ and neuropathy (RR, 0.19;95\% CI, $\left.0.14-0.27 ; \mathrm{I}^{2}=19 \% ; p<0.01\right)$ compared with PAC plus carbo. PLD plus carbo, however, was associated with an increased risk of mucositis/stomatitis (RR, 2.12; 95\% CI, $\left.1.54-2.93 ; \mathrm{I}^{2}=0 \% ; p<0.01\right)$ and hand-foot syndrome (RR, 6.12; 95\% CI, 3.84-9.76; $\mathrm{I}^{2}=0 \% ; p<0.01$ ).

Compared with grade $3-4$ severe toxicities, both handfoot syndrome and mucositis/stomatitis primarily arose with low-grade toxicities, and the patients' adverse symptoms were mild. Both anemia and thrombocytopenia were principally associated with severe toxicities. Fortunately, the adverse incidence was not high (8.2 and 14.7\%, respectively). We then laterally compared the incidence of side effects at two different PLD doses (grade 3-4 toxicity): for anemia, $30 \mathrm{mg} / \mathrm{m}^{2}$ vs. $45 \mathrm{mg} / \mathrm{m}^{2}$ PLD (8.0\% vs. $9.5 \%$, respectively), and for thrombocytopenia, $30 \mathrm{mg} / \mathrm{m}^{2}$ vs. $45 \mathrm{mg} / \mathrm{m}^{2}$ PLD ( $15.0 \%$ vs. $12.0 \%$, respectively). These two adverse reactions did not show a significant dose- dependency for PLD, which may be because the combination with carbo reduced the toxic side effects of PLD.

Our updated meta-analysis results showed that PLD plus carbo provided a non-inferior survival rate and was well tolerated. Hence, PLD plus carbo emerged as a favorable option for platinum-sensitive patients in the recurrent setting.

\section{Single regimens}

In platinum-resistant or -refractory recurrent ovarian cancer, PLD shows survival results similar to those of other single agents, and, thus, platinum-resistant women have been challenged with non-platinum drugs. One study showed that gemcitabine plus PLD was a very attractive combination given that it possessed different mechanisms of action and different toxicity profiles [26]; this combination did not reduce the individual effect of either agent, but rather increased the activity of the drugs in an additive fashion. This therapy was well tolerated by most platinum-resistant ovarian cancer patients, and patients with higher levels of baseline deoxycytidine kinase exhibited longer PFS. The usage recommended was $35 \mathrm{mg} / \mathrm{m}^{2}$ of PLD on day 1 , and $1000 \mathrm{mg} / \mathrm{m}^{2}$ of gemcitabine on days 1 and 15 q4 weeks. However, as this was a phase-Ib study, it requires further exploration. Other investigators demonstrated that olaparib combined with PLD was well tolerated, but the combination 


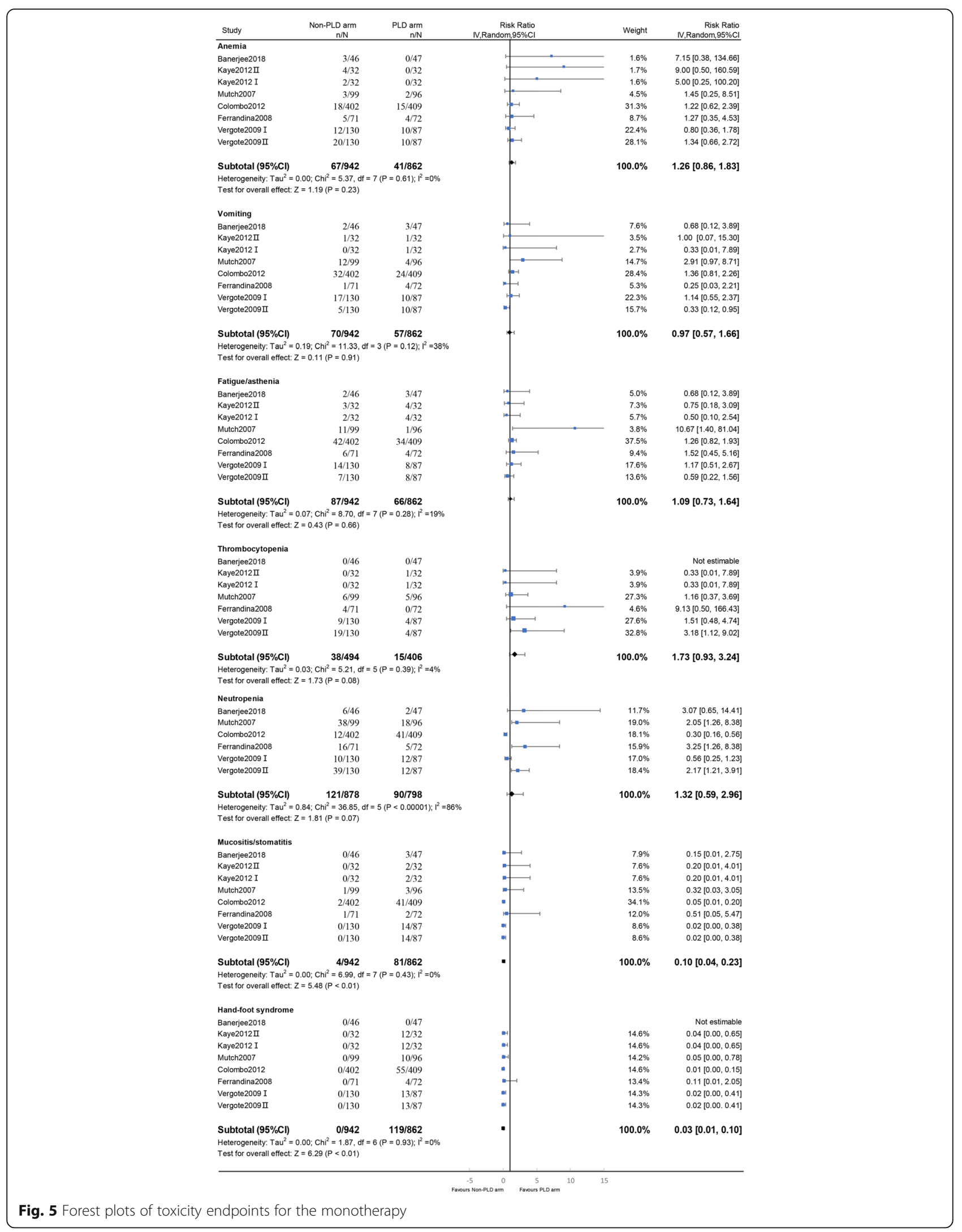


did not result in a significant prolongation of PFS or OS in platinum-resistant or -refractory ovarian cancer [27]. The 2019 NCCN Guidelines showed that PLD plus bevacizumab constitutes a potential treatment option for patients with platinum-resistant recurrent ovarian cancer, and the 2020 NCCN Guidelines suggest that bevacizumab is effective in both platinum-sensitive and platinum-resistant recurrent ovarian cancer. Nevertheless, treatment of platinum-resistant or -refractory recurrent ovarian cancer as palliative care still necessitates more chemotherapy options.

The principal and common adverse effects of monotherapy PLD were mucositis/stomatitis and hand-foot syndrome. We laterally compared the incidence of side effects at two different PLD doses (grade 3-4 toxicity), and showed that mucositis/stomatitis $\left(40 \mathrm{mg} / \mathrm{m}^{2}\right.$ vs. 50 $\left.\mathrm{mg} / \mathrm{m}^{2}\right)$ PLD (4.2\% vs. $10.2 \%$, respectively) was a dosedependent side effect of PLD. At the same doses (3.4\% vs $17.6 \%$, respectively), the results showed that handfoot syndrome was also a significant dose-dependent side effect of PLD.

Thus, our updated meta-analysis showed that PLD was well-tolerated at the $40 \mathrm{mg} / \mathrm{m}^{2}$ (lower-dose) regimenwhich did not adversely affect survival compared with other single regimens-and confirmed PLD as a good choice for women in whom monotherapy was a treatment option.

\section{Strengths and limitations of PLD in the treatment of ovarian Cancer}

The most concerning potential side effect of doxorubicin and PLD is often cited as congestive heart failure, and doxorubicin is in fact closely associated with congestive heart failure. PLD's parent drug is doxorubicin, but PLD can effectively reduce cardiac toxicity. Studies show that PLD reduced the incidence of cardiotoxicity five-to-six fold even at doses $\geq 500 \mathrm{mg} / \mathrm{m}^{2}$. This is because of pegylation, which coats the liposome with a hydrophilic protective coating, and allows the drug to remain in circulation for a prolonged time due to its ability to evade immunologic elimination. Both lower plasma levels and improved ability to target tumor tissue allow for the sparing of cardiac toxicity with PLD [28]. One study depicted no significant incidence of cardiotoxicity (as defined by 2D strain on 3D left-ventricular ejection fraction), even with high cumulative doses of PLD up to $2500 \mathrm{mg}$, and therefore long-term use appears safe [29]. Thus PLD exerts a cardioprotective effect and is more beneficial for patients with poor heart function and for elderly patients.

Contemporary studies have shown that prolonged treatment with PLD is associated with the development of secondary squamous cell carcinoma of the oral mucosa in a number of case reports [9]. In another trial, we showed that the cumulative doses of PLD in our patients prior to the development of squamous cell carcinoma were $1350 \mathrm{mg} / \mathrm{m}^{2}$ and $1142 \mathrm{mg} / \mathrm{m}^{2}$, respectively, and that it was necessary to reduce the dose, prolong the administration, and provide regular oral-cavity examinations along with complete skin examinations [30]. We recommend using a PLD dose as low as possible, and to prolong the administration so as to reduce the incidence of hand-foot syndrome-thereby reducing the incidence of secondary squamous cell carcinoma of the oral mucosa.

\section{Conclusions}

PLD plus carbo for platinum-sensitive disease produced a better PFS than standard-regimen PAC plus carbo and was well tolerated. However, there was no difference in overall survival. The findings of this meta-analysis support the continued use of PLD plus carbo as first-line chemotherapy for platinum-sensitive recurrent ovarian cancer, and PLD at $30 \mathrm{mg} / \mathrm{m}^{2}$ every 4 weeks can be used as the initial dose. As a single-agent therapy, PLD manifested survival similar to other agents and was well tolerated. The findings of this meta-analysis support the continued use of PLD monotherapy as first-line chemotherapy for platinum-resistant or -refractory recurrent ovarian cancer, and we recommend using PLD at a dose of $40 \mathrm{mg} / \mathrm{m}^{2}$ every 4 weeks as the initial dose.

\section{Abbreviations \\ NCCN: National comprehensive cancer network; PLD: Pegylated liposomal doxorubicin; PAC: Paclitaxel; Carbo: Carboplatin; LIFA: Lifastuzumab vedotin; OS: Overall survival; PFS: Progression-free survival; HR: Hazard ratios; RR: Risk ratios; 95\% Cl: 95\% Confidence interval.}

\section{Supplementary Information}

The online version contains supplementary material available at https://doi. org/10.1186/s13048-021-00790-4.

Additional file 1.

Additional file 2.

\section{Acknowledgements}

We would like to thank all authors who provided published data for our meta-analysis.

\section{Authors' contributions}

All authors contributed to the design of the review. X.R.L and L.X.P completed the initial data search. Y.Z and J.M.H designed methods and completed the Statistical analysis. G.N.Z co-designed methods and revised the article. X.R.L wrote the first manuscript draft and all authors approved the final manuscript.

\section{Funding}

This work was supported by National Natural Science Foundation of China (grant numbers 81902670), Sichuan Key Research and Development Project from Sichuan Provincial Science and Technology Department (grant numbers 2019YFS0424 and 2019YFS0036). 


\section{Availability of data and materials}

The dataset used or analyzed in this study is available from the corresponding author upon reasonable request.

\section{Declarations}

Ethics approval and consent to participate

Not applicable.

\section{Consent for publication}

Not applicable.

\section{Competing interests}

All the authors declare no competing interests.

\section{Author details}

${ }^{1}$ Hospital of Chengdu University of Traditional Chinese Medicine, Chengdu 610072, Sichuan Province, People's Republic of China. ${ }^{2}$ Department of Ultrasound, the Affiliated Cancer Hospital, School of Medicine, University of Electronic Science and Technology of China, Sichuan Cancer Hospital \& Institute, Chengdu 610041, Sichuan Province, People's Republic of China. ${ }^{3}$ Department of Gynecological Oncology, the Affiliated Cancer Hospital, School of Medicine, University of Electronic Science and Technology of China, Sichuan Cancer Hospital \& Institute, No.55 Ren-min-nan Road, Chengdu 610041, Sichuan Province, People's Republic of China. ${ }^{4}$ School of Clinical Medicine, Chengdu University of Traditional Chinese Medicine, No.37 Shi-er-qiao Road, Chengdu 610072, Sichuan Province, People's Republic of China. ${ }^{5}$ Department of Biochemistry \& Molecular Biology, the Affiliated Cancer Hospital, School of Medicine, University of Electronic Science and Technology of China, Sichuan Cancer Hospital \& Institute, Chengdu 610041, Sichuan Province, People's Republic of China.

\section{Received: 13 February 2021 Accepted: 26 February 2021} Published online: 09 March 2021

\section{References}

1. Reid BM, Permuth JB, Sellers TA. Epidemiology of ovarian cancer: a review. Cancer biology and. Medicine. 2017;14:9-32.

2. Piao J, Lee EJ, Lee M. Association between pelvic inflammatory disease and risk of ovarian cancer: An updated meta-analysis. Gynecol Oncol. 2020;157:542-8.

3. Bookman MA, Okamoto A, Stuart G, Yanaihara N, Aoki D, Bacon M, et al. Harmonising clinical trials within the gynecologic cancer intergroup: consensus and unmet needs from the fifth ovarian cancer consensus conference. Ann Oncol. 2017:28:viii30-5.

4. McGee J, Bookman M, Harter P, Marth C, McNeish I, Moore KN, et al. Fifth ovarian cancer consensus conference: Individualized therapy and patient factors. Ann Oncol. 2017;28:702-10.

5. Landrum LM, Brady WE, Armstrong DK, Moore KN, DiSilvestro PA, O'Malley DM, et al. A phase I trial of pegylated liposomal doxorubicin (PLD), carboplatin, bevacizumab and veliparib in recurrent, platinum-sensitive ovarian, primary peritoneal, and fallopian tube cancer: An NRG oncology/ gynecologic oncology group study. Gynecol Oncol. 2016;140:204-9.

6. Buechel M, Herzog TJ, Westin SN, Coleman RL, Monk BJ, Moore KN. Treatment of patients with recurrent epithelial ovarian cancer for whom platinum is still an option. Ann Oncol. 2019;30:721-32.

7. Corrado G, Salutari V, Palluzzi E, Distefano MG, Scambia G, Ferrandina G. Optimizing treatment in recurrent epithelial ovarian cancer. Expert Rev Anticancer Ther. 2017;17:1147-58.

8. Madrid Paredes A, Vallejo I, Carrasco M, Valencia C, Artime F, Calleja M. Prescription profile and impact after the pegylated liposomal doxorubicin shortage alert. Eur J Hosp Pharm. 2015;22:A16.

9. Cannon TL, Lai DW, Hirsch D, Delacure M, Downey A, Kerr AR, et al. Squamous cell carcinoma of the oral cavity in nonsmoking women: A new and unusual complication of chemotherapy for recurrent ovarian cancer? Oncologist. 2012;17:1541-6.

10. Gibson JM, Alzghari S, Ahn C, Trantham H, La-Beck NM. The role of pegylated liposomal doxorubicin in ovarian cancer: a meta-analysis of randomized clinical trials. Oncologist. 2013;18:1022-31.

11. Lawrie TA, Bryant A, Cameron A, Gray E, Morrison J. Pegylated liposomal doxorubicin for relapsed epithelial ovarian cancer. Cochrane Database Syst Rev. 2013;7:CD006910.
12. Pujade-Lauraine E, Wagner U, Aavall-Lundqvist E, Gebski V, Heywood M, Vasey PA, et al. Pegylated liposomal doxorubicin and carboplatin compared with paclitaxel and carboplatin for patients with platinum-sensitive ovarian cancer in late relapse. J Clin Oncol. 2010;28:3323-9.

13. Gladieff L, Ferrero A, De Rauglaudre G, Brown C, Vasey P, Reinthaller A, et al. Carboplatin and pegylated liposomal doxorubicin versus carboplatin and paclitaxel in partially platinum-sensitive ovarian cancer patients: Results from a subset analysis of the CALYPSO phase III trial. Ann Oncol. 2012;23:1185-9.

14. Mahner S, Meier W, Du Bois A, Brown C, Lorusso D, Dell'Anna T, et al. Carboplatin and pegylated liposomal doxorubicin versus carboplatin and paclitaxel in very platinum-sensitive ovarian cancer patients: Results from a subset analysis of the CALYPSO phase III trial. Eur J Cancer. 2015;51:352-8.

15. Bafaloukos D, Linardou H, Aravantinos G, Papadimitriou C, Bamias A, Fountzilas G, Kalofonos HP, Kosmidis P, Timotheadou E, Makatsoris T, Samantas E, Briasoulis E, Christodoulou C, Papakostas P, Pectasides D, Dimopoulos AM. A randomized phase II study of carboplatin plus pegylated liposomal doxorubicin versus carboplatin plus paclitaxel in platinum sensitive ovarian cancer patients: a Hellenic Cooperative Oncology Group study. BMC Med. 2010;8:3.

16. Mutch DG, Orlando M, Goss T, Teneriello MG, Gordon AN, McMeekin SD, et al. Randomized phase III trial of gemcitabine compared with pegylated liposomal doxorubicin in patients with platinum-resistant ovarian cancer. J Clin Oncol. 2007;25:2811-8.

17. Ferrandina G, Ludovisi M, Lorusso D, Pignata S, Breda E, Savarese A, et al. Phase III trial of gemcitabine compared with pegylated liposomal doxorubicin in progressive or recurrent ovarian cancer. J Clin Oncol. 2008;26:890-6.

18. Vergote I, Finkler NJ, Hall JB, Melnyk O, Edwards RP, Jones M, et al. Randomized phase III study of canfosfamide in combination with pegylated liposomal doxorubicin compared with pegylated liposomal doxorubicin alone in platinum-resistant ovarian cancer. Int J Gynecol Cancer. 2010;20:772-80.

19. Colombo N, Kutarska E, Dimopoulos M, Bae DS, Rzepka-Gorska I, Bidzinski M, et al. Randomized, open-label, phase III study comparing patupilone (EPO906) with pegylated liposomal doxorubicin in platinum-refractory or -resistant patients with recurrent epithelial ovarian, primary fallopian tube, or primary peritoneal cancer. J Clin Oncol. 2012;30:3841-7.

20. Banerjee S, Oza AM, Birrer MJ, Hamilton EP, Hasan J, Leary A, et al. Anti$\mathrm{NaPi}$ b antibody-drug conjugate lifastuzumab vedotin (DNIB0600A) compared with pegylated liposomal doxorubicin in patients with platinumresistant ovarian cancer in a randomized, open-label, phase II study. Ann Oncol. 2018;29:917-23.

21. Kaye SB, Lubinski J, Matulonis U, Ang JE, Gourley C, Karlan BY, et al. Phase II, open-label, randomized, multicenter study comparing the efficacy and safety of olaparib, a poly (ADP-ribose) polymerase inhibitor, and pegylated liposomal doxorubicin in patients with BRCA1 or BRCA2 mutations and recurrent ovarian cancer. J Clin Oncol. 2012;30:372-9.

22. Wilson MK, Pujade-Lauraine E, Aoki D, Mirza MR, Lorusso D, Oza AM, et al. Fifth ovarian cancer consensus conference of the gynecologic cancer intergroup: recurrent disease. Ann Oncol. 2017;28:727-32.

23. Rolim LC, da Silva EMK, Flumignan RLG, Abreu M, Dib SA. Cochrane systematic review of acetyl-L-Carnitine for the treatment of diabetic polyneuropathy. Eur J Vasc Endovasc Surg. 2019;58:e342-3.

24. Colombo N, Sessa C, du Bois A, Ledermann J, McCluggage WG, McNeish I, et al. ESMO-ESGO consensus conference recommendations on ovarian cancer: pathology and molecular biology, early and advanced stages, borderline tumours and recurrent disease. Ann Oncol. 2019;30:672-705.

25. Bergamini A, Pisano C, Di Napoli M, Arenare L, Della Pepa C, Tambaro R, et al. Cisplatin can be safely administered to ovarian cancer patients with hypersensitivity to carboplatin. Gynecol Oncol. 2017;144:72-6.

26. Crespo G, Sierra M, Losa R, Berros JP, Villanueva N, Fra J, et al. Pegylated liposomal doxorubicin and gemcitabine in a fixed dose rate infusion for the treatment of patients with poor prognosis of recurrent ovarian cancer: A phase Ib study. Int J Gynecol Cancer. 2011;21:478-85.

27. McGuire WP, Penson RT, Gore M, Herraez AC, Peterson P, Shahir A, llaria R Jr. Randomized phase II study of the PDGFRa antibody olaratumab plus liposomal doxorubicin versus liposomal doxorubicin alone in patients with platinum-refractory or platinum-resistant advanced ovarian cancer. BMC Cancer. 2018:18:1292.

28. Gabizon AA, Patil Y, La-Beck NM. New insights and evolving role of pegylated liposomal doxorubicin in cancer therapy. Drug Resist Updat. 2016:29:90-106. 
29. Blank N, Laskov I, Kessous R, Kogan L, Lau S, Sebag IA, et al. Absence of cardiotoxicity with prolonged treatment and large accumulating doses of pegylated liposomal doxorubicin. Cancer Chemother Pharmacol. 2017;80: 737-43.

30. Pease DF, Peterson BA, Gilles S, Hordinsky MK, Bohjanen KA, Skubitz KM. Development of cutaneous squamous cell carcinoma after prolonged exposure to pegylated liposomal doxorubicin and hand-foot syndrome: a newly recognized toxicity. Cancer Chemother Pharmacol. 2019;84:217-21.

\section{Publisher's Note}

Springer Nature remains neutral with regard to jurisdictional claims in published maps and institutional affiliations.

Ready to submit your research? Choose BMC and benefit from:

- fast, convenient online submission

- thorough peer review by experienced researchers in your field

- rapid publication on acceptance

- support for research data, including large and complex data types

- gold Open Access which fosters wider collaboration and increased citations

- maximum visibility for your research: over $100 \mathrm{M}$ website views per year

At BMC, research is always in progress.

Learn more biomedcentral.com/submissions 